\title{
Building Capacity for Research and Audit: Outcomes of a Training Workshop for Pacific Physicians and Nurses
}

\author{
Alec J. Ekeroma ${ }^{1,2}$, Tim Kenealy ${ }^{2}$, Boaz Shulruf ${ }^{3}$, Vili Nosa ${ }^{4}$, Andrew Hill ${ }^{2}$ \\ ${ }^{1}$ Pacific Women's Health Research Unit, Department of Obstetrics and Gynaecology, South Auckland Clinical Campus, \\ University of Auckland, New Zealand \\ ${ }^{2}$ South Auckland Clinical Campus, University of Auckland, New Zealand \\ ${ }^{3}$ Office of Medical Education, Faculty of Medicine, University of New South Wales, Sydney, New South Wales, \\ Australia \\ ${ }^{4}$ Pacific Health, School of Population Health, University of Auckland, New Zealand \\ Correspondence: Alec J. Ekeroma, Pacific Women's Health Research Unit, South Auckland Clinical Campus, \\ University of Auckland, Middlemore Hospital, Auckland, New Zealand
}

Received: April 21, 2015 Accepted: May 15, $2015 \quad$ Online Published: June 10, 2015

doi:10.11114/jets.v3i4.774

URL: http://dx.doi.org/10.11114/jets.v3i4.774

\begin{abstract}
Building the research capacity of clinicians in the Pacific Island countries is important in addressing evidence gaps relevant to local policy and clinical practice. This paper aimed to assess the effectiveness of a reproductive health research workshop in increasing research knowledge and intention to perform research amongst a diverse group of clinicians. An online survey of clinicians and stakeholders in the Pacific Islands informed a research workshop curriculum. Physicians and nurses/midwives $(n=28)$ from six Pacific Island countries were selected as workshop participants as part of a research capacity building program. Questionnaires before after the workshop were used to measure the changes in knowledge, confidence, competence, attitudes and intention to perform research and these were analysed thematically.

Sixty-three of $85(74 \%)$ stakeholders and clinicians responded to an online survey, which informed workshop curriculum development. Of the 28 workshop participants, seven were obstetrician-gynaecologists, eight junior physicians and eleven nurses/midwives. The mean pre-test score was $36 \%( \pm 10)$ and the post-test was $43 \%( \pm 6)$ $(\mathrm{p}<0.01)$. By profession, the obstetricians had higher prior research knowledge whereas nurses had a higher knowledge gain after the workshop. Attitude, intention and motivation to perform research was high and the participants learnt that research is important, to start small; to use routinely collected data; to encourage others to do research; and to network regionally.

This paper has confirmed that online surveys, in low resource settings, can have an acceptable response rate. It has also shown that a research workshop for a diverse group of clinicians can be effective in increasing knowledge although knowledge gained was more significant amongst nurses/midwives compared to physicians. The other benefits of the research workshop were increased motivation and attitudes for research, which if well supported, should result in an increase in research output in the Pacific Islands. Future evaluation will assess the long-term effectiveness of annual research workshops and mentoring support in improving research performance and evidence utilisation in care.
\end{abstract}

Keywords: Pacific Islands, research capacity, research workshops, research needs, research knowledge, low and middle-income countries

\section{Introduction}

Research capacity building programmes in low to middle income countries (LMIC) is an essential component of strengthening health systems (Pang \& Terry, 2011), addressing inequities in health care (Bamako call to action on research for health; COHRED, 2012) and sustainable social and economic development (R. Thomas \& Wilson, 2010). International agencies, for the last three decades, have called for an increase in investment for research development in LMIC (Bamako call to action on research for health; World Health Organisation Report, 2007) which have been largely directed to research collaborations, strengthening governance, infrastructure and the training of research scientists. 
There is an increasing realisation however that training clinicians, comprised mostly of nurses and physicians, to perform research has an advantage over training pure researchers (Back, Book, Santos, \& Brady, 2011; Page et al., 2003), as clinicians tend to know the clinical needs and research questions, and they will most likely utilise research evidence (Kahn et al., 2011). But despite the huge research investment efforts and an ongoing shortage of scientists in LMIC, there is a limited number of papers detailing interventions, such as workshops, to develop clinicians as researchers (Cole et al., 2012).

The Pacific Society for Reproductive Health (PSRH), with a large membership of reproductive health workers in thirteen Pacific Island countries, conducted three research workshops (2009, 2011 and 2013) for clinicians in response to the lack of reproductive health research in the region (Ekeroma et al., 2013; World Health Organization, 2007). The Society decided in 2013 to develop a programme called the Building Reproductive Research and Audit Capacity and Activity in the Pacific (BRRACAP) Study (Ekeroma, Kenealy, Shulruf, McCowan, \& Hill, 2014) that would include evaluating effectiveness of research workshops. Research workshops form an important primary component of research capacity building programmes and their effectiveness has been measured in knowledge and skills gained (Ajuwon \& Kass, 2008; Bates et al., 2007; Goto, Nguyen, Nguyen, \& Hughes, 2005). Evidence of publication output, following training workshops, which were not part of a research capacity building programme, have been limited due to short-term follow-up (Sunita Dodani \& LaPorte, 2008) for instance. The only other workshop performed in the Pacific Islands with a wide spectrum of participants used the participant's one-minute reflections as a measure of effectiveness (Redman-Maclaren et al., 2010).

There have been limited opportunities for reproductive health clinicians in the Pacific Islands to attend research workshops and there is a need to evaluate the effectiveness of introduced research capacity building interventions (Bates et al., 2007). Further, any research workshops in the Pacific Islands would have to address the training needs of nurses and physicians in clinical teams as we had emphasized that clinical research was clinical team-work. There have been no studies that have compared the effectiveness of research workshops on nurses and physicians attending the same workshop. This paper reports on the process and the immediate outcomes of the first research-training workshop within the BRRACAP Study (Ekeroma et al., 2014). We were also interested in the process of devising a research workshop curriculum and how the participants perceived the workshop content and delivery.

\section{Method}

\subsection{Selection of Participants and Funding}

Twenty-eight clinicians with different roles and educational backgrounds were selected by the PSRH and Ministries of Health from five Pacific Island countries - Vanuatu, Solomon Islands, Samoa, Cook Islands, Tonga - and the Fiji National University. It was considered that five clinicians from each country would be needed to provide a critical mass to support and sustain clinical research in reproductive health in that country - an acknowledgement that research is more successful with group effort. There is a shortage of clinicians in the Pacific Islands and most countries have only one departmental team, which is much smaller than those in developed country hospitals. After discussions with employers, five was considered an adequate number of clinicians, as determined by the available resources for the workshop, the largest number of participants that will enable small class learning and the largest permissible number of clinicians from a single service allowed leave from work at the same time.

The countries were selected to represent the diversity of Pacific cultures, economies and infrastructures within Melanesia and Polynesia. The selection criteria agreed with the employers were: an active clinician (doctor, midwife, nurse and clinician manager) working in reproductive health; wanting to learn and do research/clinical audit; preferably in a leadership role; having performed research and being a member of the PSRH. Clinical leaders in the Pacific Islands have influence over: the allocation of team-members duties; a supportive working environment for research; and the evidence used in clinical practice. There is evidence that effective leaders lead by example and performing or advocating for research can enhance the research environment. With the exception of three participants, all were drawn from the main or biggest hospital of each of the participating Island states, as they would have better access to resources and proximity to members of their team. The limit in participant numbers prevented including more clinicians from the six Islands and other Island states.

An intentional aspect of the workshop design was to recruit physicians and nurses to create a mixed class of learners from different backgrounds and with different learning needs. Physicians/Obstetricians and nurses/midwives learn and work in a team setting in the Pacific Islands and performing research together should enhance the inter-disciplinary collaboration that already exists. Obstetrians are heads of departments and reproductive health team leaders and there may be only one or two on an Island country. We have not found a study that looked specifically at the effectiveness of a research workshop with mixed participants of physicians and nurses.

A decision was made to hold the workshop in Auckland New Zealand as that was where the Secretariat of the PSRH 
was situated, where a substantial Pacific research workforce already exists, and utilising the research faculty resources available to the lead author, from the University of Auckland. Having the workshop away from the participants' workplace reduces pressure on them to work and family duties.

Employers were asked to provide support for their clinicians by meeting their return airfares to New Zealand, allocating 5 hours a week for research and to assist with Internet costs and connection. The World Health Organization, United Nations Fund for Population Health, PSRH Charitable Trust, Pacific Health Research Foundation and donations met the remainder of the total cost of NZ\$70,000 including airfares. The ideal size of the class, rather than the funding, limited the number of participants.

Ethical approval was gained for this study from the University of Auckland Human Participants Ethics Committee (Ref. No. 8373).

\subsection{Needs Analysis - Workshop Curriculum}

To inform and refine the objectives and curriculum of the workshop, a needs analysis survey was conducted using SurveyMonkey (Wright, 2005). A series of three emails were used to invite 85 key stakeholders, clinical leaders, and experienced researchers with Pacific connections, known to the principal investigator, to participate. Since the survey was conducted prior to finalising participant selection to the workshop, not all the final participants had an invitation to complete the survey.

\subsection{Needs Analysis and Training Approach}

The results of the Needs Analysis survey, combined with evidence from the literature were incorporated into designing the workshop curriculum detailed ina previous publication (Ekeroma et al., 2014). The workshop incorporated 48 hours of seminars, lectures and small group work over six days. The objectives of the workshop were to: teach the basic components of audit and research principles and knowledge; to develop basic audit and research skills; to build a positive attitude to research and evidence-based care and to develop research/audit projects that could be completed by the participants, with support, within 18 months of the workshop.

The curriculum was delivered by a combination of didactic lectures, interactive group discussions and group-work. Country groups discussed the nature and methods of research and audit projects they would like to perform on their return. The participants were taught different research methods and were expected to adopt methods appropriate for their research project. Lecture materials were provided to the participants and were also posted online (www.psrh.org.nz) for easy access and download. The workshop was also to develop a positive attitude for research and audit by having motivational talks aimed to inspire the participants to believe that doing research was possible even for those who had not done this previously. Participants were encouraged to work within small groups consisting of others from their own country to develop projects that were priority to their service. Most of the teaching faculty were established researchers with research experience in the Pacific Islands from the University of Auckland. The participants were assigned an experienced research mentor to assist and guide them complete their projects.

\subsection{Measures of Workshop Outcomes}

The key outcome measures for the workshop were: a measured increase in research/audit knowledge and skills and whether gains were similar between nurses and doctors; an increase in positive attitude to research and satisfactory development of projects.

Questionnaires and course evaluations tools to measure outcomes were based on previous pre-workshop and postworkshop tests, measures used in research workshops for clinicians in LMIC (Ajuwon \& Kass, 2008; Bates et al., 2007; Sunita Dodani \& LaPorte, 2008; Goto et al., 2005; Redman-Maclaren et al., 2010; Tomatis et al., 2011). Tools used to measure outcomes of research courses in LMIC longer than three weeks such as project reports (Bates et al., 2007) and publications (Bissell et al., 2014) were not used.

\subsection{Pre- and Post-workshop Questionnaires}

The Pre and Post-Workshop Questionnaires (Table 1) were designed and structured from the Harvard Graduate School of Education questionnaire (Smith \& Bingman, 2007) although the actual questions were made course-specific. They assessed knowledge of research methods and principles prior to and after the workshop. The questionnaires, in addition, explored participants' awareness of routinely collected data in their settings and how these can be analysed for information that can guide service delivery. Questions were both closed response and in short open text format and were piloted using cognitive interviewing (Presser, Rothgeb, \& Couper, 2004).

Two tables of additional questions (Appendix A) were added to the post-workshop questionnaire. The first one was to measure stages of change model of evaluation in attitudes, intentions and actions (Buckley, Goering, Parikh, Butterill, \& Foo, 2003), as was used by Bates et al in Ghana (Bates et al., 2007). The second table of questions was to measure 
confidence in performing research. The questionnaire took a variable amount of time to complete and the participants were given the questionnaires to complete in their rooms overnight.

All completed questionnaires were marked from an answer schedule by two independent researchers who were not aware of which papers were pre or post-workshop and they marked independently. The free text answers were marked against pre-determined criteria with the total possible mark given for each section given to the markers. The total maximum scores were for the Pre-Test questionnaire 74 and the Post-Test 79. These were scaled to a total possible score of $100 \%$ per questionnaire.

\subsection{Workshop Evaluation}

As well as morning recap on the learning from the day before, the participants completed an evaluation questionnaire on the last day of the workshop. The evaluation aimed to assess satisfaction with workshop process, content and confidence in the performance of certain skills. Some of the questions were open-ended and the questionnaire (Appendix B) had been piloted with members of the organising team. 
Table 1. Pre and Post-workshop Questionnaire

\section{Importance of research and audit}

a. Do you know of a research project or clinical audit in your department or hospital in the past 5 years?

Knowledge of audit in department (1mark per audit topic; 0 for No) up to 5 marks

b. Was this/were these important pieces of work? And why? (PreTest Only)

Knowledge of Importance (1mark per answer)

c. Were the findings of the research/audit project used in clinical practice?

Knowledge question ( 1 mark if have knowledge of use per clinical guideline)

d. If you are not aware of any research or audit work in your country, how would you search for this information?

Ask head of unit/department; research office; search Internet (a mark for each)

e. Why is research performed in the Pacific important?

Inform/improve policy, inform/improve practice, evidence in context (1mark each)

\section{Definitions and concepts}

a. How do you define epidemiology?

Is the study of disease on a population basis (2 marks)

b. What is the difference between quantitative and qualitative research?

Qualitative research attempts to understand why things are whereas quantitative research attempts to understand what the problems are. The former uses tools such as in depth interviews and questionnaires whereas the latter uses tools such as RCTs and analysis of numbers whether retrospective or prospective. ( 3 marks)

c. How do you define mean, mode and range in statistics?

Mean is the average after the total sum is divided by the number of subjects

Mode is the middle number when arranged in order from the lowest to the highest

Range is the range of numbers from the least to the largest ( 3 marks)

d. What are the differences between audit and research? (PreTest Only)

Audit looks at how effective a policy, process or practice has been delivered. It answers the question: "How are we doing?" It usually does not need ethics approval. Research usually has a hypotheses, it can be experimental or observational and can attempts to answer the question: "What should we do?" It always needs ethics approval. (No Marks)

\section{Datasets}

a. List 5 datasets or variables you are collecting in your everyday work.

One mark per variable or dataset to 5 marks ( 5 marks)

b. What is the best way of collecting the first three variables from your answer in (a)?

Paper as in a book, a template or form that is collected, computerized databases, any other reasonable method (one mark each) (3 marks)

c. What information will you want to obtain from the first variable you listed in (a)?

e.g. ethnic group would determine which ethnic group was most affected by a condition; parity - would determine an association between the condition measured and parity of the woman, etc ( 1 mark each for any reasonable answer) (1 mark)

c. To obtain the information in (c) above, will you do an audit or research project? If it's a research project, what type of research methodology would you use? (PostTest Only)

The answer depends on the variables collected in above answer and intention for the

variables. The answer should also reflect knowledge of methodology. (Give total mark out of 5). (5 marks)

d. How will you analyse the data?

Knowledge of analysis - Excel, Epi Info, other stats packages. Or ask someone

(statistician) to do it. (marks out of 5). (5 marks)

\section{A practical example}

a. How will you obtain data on married women's contraceptive preferences in your community?

The participant will be required to demonstrate knowledge of local data sources and systems (eg. health centre, community nurse), or the cultural context in which a researcher/health worker needs to operate in so that the data can be collected sensitively. Knowledge of sampling will also be good. (5 marks)

b. What difficulties may you encounter?

Women in the village may be reluctant to reveal sensitive information about contraception ( 5 marks)

c. Are you aware of a Pacific research methodology that can be used to collect this data?

There are several which includes the Talanoa, Tivaevae, Faafaletui models which are qualitative research techniques encompassing of understanding and respecting Pacific cultures whilst collecting the information using conversation and story telling. They are similar to participatory action research methodology. (5 marks)

\section{Tools and skills}

a. What tools would you need in order to perform an audit project?

a computer, a spreadsheet, library or internet, ability to collect data, a data set repository (5 marks)

b. What tools would you need for a research project in your setting?

A research team, stakeholders, different skills, a computer, a spreadsheet, a statistical package, internet access, (5 marks)

c. What skills would do you think you will need to produce a research paper?

Answer in B above and then good writing skills, skills with EndNote or similar program (5 marks).

d. What support do you think you will need to perform a research project? (PostTest Only)

Department, supervisor/manager, ethics committee, research committee, research team (5 marks) 


\subsection{Data Analysis}

Deductive and inductive approaches were used to identify themes consistent with the question schedule embedded in the data. The data were coded and emerging themes were used to build a thematic framework, to which the participant responses were categorized (Spencer, Ritchie, \& O'Conner, 2003; D. Thomas, 2006). Quantitative data were downloaded into an Excel spreadsheet where it was sorted and initially analysed. Statistical software used was SPSS version 22 (Boston Inc.) and we used ANOVA to test the effects of gender, role and Masters degree on the difference per person from pre to post-test.

\section{Results}

\subsection{Research Needs Analysis - Online Questionnaire Pre-workshop}

There were 63 respondents from 85 stakeholders to the SurveyMonkey® survey on research needs of clinicians in the Pacific, giving a response rate of 74\%. The survey was open from January to July 2013 and 59 of the respondents replied prior to the workshop in March 2013. Professional roles of respondents were: medical doctor 32 (51\%), nurse/midwife $14(22 \%)$, researcher $7(11 \%)$, manager $23 \%)$, teacher $2(3 \%)$, other $6(10 \%)$. Respondents' main country of residence were: Fiji 14 (22\%), Samoa 9 (14\%), Solomon Islands 8 (13\%), Vanuatu 4(6\%), Tonga 3 (5\%), Australia 5(8\%), New Zealand 5(8\%), Other Pacific Islands 13(21\%).

Respondents were asked which topics were most needed in a training programme. Most (>70\%) respondents prioritised: developing guidelines, implementing clinical audit findings, learning clinical audit and quality improvement, essential research skills and tools, support for Pacific research and researchers, learn to write a research project putting research findings in to action, project funding, statistics, questionnaire design, measurement tools, write a publication, data collection, qualitative and quantitative research, ethics, research networks, Pacific research methodologies, research methods and data organisation.

Respondents were also asked which skills participants would most need. Most (>70\%) respondents prioritised: how to analyse data, how to write a research paper, how to critique a research paper, decide which data to collect, how to present data, how to write an audit paper, how to frame a research question and use of referencing library. They were also asked which research outputs and outcomes were most important to them. Most (>70\%) respondents listed: presentation at a regional conference, write a research proposal, increase in research knowledge, research publication in a peer- reviewed journal, completion of an audit project and success at obtaining funding.

\subsection{Characteristics of the Workshop Participants}

Most of the participants were physicians $(17,61 \%)$ and most had more than one role. Most had a post-graduate diploma or a Masters degree $(23,82 \%)$. The age range of participants was 28 to 55 years with a median age of 40 . There were 20 women and eight men.

\subsection{Knowledge gained - Pre and Post-test Questionnaires $(n=26)$}

The mean score (SD) for the pre-test was $36 \%( \pm 11)$ and the post-test was $43 \%( \pm 6)$. The difference of the mean was $6.7 \%( \pm 12)(\mathrm{p}=0.008(95 \% \mathrm{CI}:-11.54$ to -1.92$)$. Five participants scored $>45 \%$ in the pre-test and the same individuals scored $<45 \%$ in the post-test.

By qualification, the 11 participants with Master's degrees gained five absolute points although this was not significant. In contrast, those without a Masters degree had a similar level of prior research knowledge and yet gained eight points, but this was also not significant (Table 2). Role as a group was statistically significantly associated with gain in pre to post-test score. Post-hoc testing showed the Midwife/nurse group to be significantly different from the Obstetricians but not the Other group.

Table 2. Pre and Post-test scores by qualification, profession and gender.

\begin{tabular}{lllll}
\hline Group & $\begin{array}{l}\text { Pre-test } \\
\text { mean (SD) }\end{array}$ & $\begin{array}{l}\text { Post-test } \\
\text { mean (SD) }\end{array}$ & $\begin{array}{l}\text { Absolute gain } \\
(\mathrm{SD})\end{array}$ & P value \\
\hline Masters $(\mathrm{n}=11)$ & $37(11.0)$ & $41(7.9)$ & $4.6(9.1)$ & 0.45 \\
No Masters $(\mathrm{n}=15)$ & $35(10.6)$ & $44(5.0)$ & $8.3(13.7)$ & \\
Obstetrician $(\mathrm{n}=7)$ & $42(12.2)$ & $41(7.3)$ & $-1.0(11.8)$ & 0.04 \\
Midwife/Nurse (n=11) & $30(7.3)$ & $43(6.0)$ & $13.1(10.4)$ & \\
Others ( $=8)$ & $40(9.8)$ & $44(6.3)$ & $4.8(10.2)$ & \\
Male (n=8) & $38(13.3)$ & $39(5.0)$ & $1.1(13.4)$ & 0.11 \\
Female (n=18) & $35(9.4)$ & $44(6.3)$ & $9.2(10.6)$ & \\
\hline
\end{tabular}

3.4 Attitude and Confidence

Twenty-three participants 'generally agreed' or 'strongly agreed' that they should do more research, whereas two 
participants did not agree (Table 3). All the participants had intentions to learn more about research or to use research evidence in practice although six participants did not report intended actions that were conducive to supporting research. Eighteen $(69 \%)$ of the participants either 'generally agreed' or 'strongly agreed' they had acquired the various research skills during the workshop (Table 4).

Table 3. Stages of change questions on Attitude, Intention and Action for research.

\begin{tabular}{|c|c|c|c|c|}
\hline $\begin{array}{l}\text { Questions on } \\
(\mathrm{n}=26: 15 \text { doctors, } 11 \text { nurses)* }\end{array}$ & $\begin{array}{l}\text { Strongly } \\
\text { Disagree }\end{array}$ & $\begin{array}{l}\text { Generally } \\
\text { Disagree }\end{array}$ & $\begin{array}{l}\text { Generally } \\
\text { Agree }\end{array}$ & $\begin{array}{l}\text { Strongly } \\
\text { Agree }\end{array}$ \\
\hline $\begin{array}{l}\text { Learning research skills is important (doctors, } \\
\text { nurses) }\end{array}$ & & & $3(1,2)$ & $22(14,8)$ \\
\hline $\begin{array}{l}\text { Understanding how to do research is important in } \\
\text { my work (doctors, nurses) }\end{array}$ & & & $3(2,1)$ & $21(13,9)$ \\
\hline $\begin{array}{l}\text { I should incorporated research findings into my } \\
\text { clinical practice (doctors, nurses) }\end{array}$ & & & $5(2,3)$ & $20(13,10)$ \\
\hline $\begin{array}{l}\text { I should do more research myself (doctors, } \\
\text { nurses) }\end{array}$ & $1(1,0)$ & & $5(5,0)$ & $19(9,10)$ \\
\hline $\begin{array}{l}\text { Understanding how to do research is relevant to } \\
\text { my work (doctors, nurses) }\end{array}$ & & & $6(5,1)$ & $17(8,9)$ \\
\hline Total responses (mean number of participants) & $1(0.2)$ & & $22(4.4)$ & $100(20.0)$ \\
\hline \multicolumn{5}{|l|}{ Questions on Intentions } \\
\hline $\begin{array}{l}\text { I plan to learn more about how to do research } \\
\text { (doctors, nurses) }\end{array}$ & & & $3(3,0)$ & $22(12,10)$ \\
\hline $\begin{array}{l}\text { I will bring up the idea of incorporating research } \\
\text { into our work with colleagues (doctors, nurses) }\end{array}$ & & & $4(3,1)$ & $21(12,9)$ \\
\hline $\begin{array}{l}\text { I plan to include use of research findings in my } \\
\text { clinical practice (doctors, nurses) }\end{array}$ & & & $2(2,0)$ & $23(13,10)$ \\
\hline $\begin{array}{l}\text { I will suggest that we discuss how to improve our } \\
\text { use of research results at our departmental } \\
\text { meetings (doctors, nurses) }\end{array}$ & & & $4(4,0)$ & $21(11,10)$ \\
\hline $\begin{array}{l}\text { Total responses (mean number of participants) } \\
\text { Ouestions on Actions }\end{array}$ & & & $13(3.3)$ & 87 (21.8) \\
\hline $\begin{array}{l}\text { I am currently working on another research } \\
\text { project (doctors, nurses) }\end{array}$ & $3(1,2)$ & $5(2,3)$ & $7(3,4)$ & $8(7,1)$ \\
\hline $\begin{array}{l}\text { I have spoken in a formal meeting about } \\
\text { increasing the use of research/guidelines in our } \\
\text { unit (doctors, nurses) }\end{array}$ & $2(1,1)$ & $7(3,4)$ & $6(4,2)$ & $10(7,3)$ \\
\hline $\begin{array}{l}\text { I have suggested casually to some of my } \\
\text { colleagues that they should do research (doctors, } \\
\text { nurses) }\end{array}$ & $1(0,1)$ & & $13(9,4)$ & $11(6,5)$ \\
\hline $\begin{array}{l}\text { I have changed my clinical practice as a result of } \\
\text { doing research (doctors, nurses) }\end{array}$ & $3(1,2)$ & $1(0,1)$ & $8(5,3)$ & $12(9,4)$ \\
\hline Total responses (mean number of participants) & $9(2.3)$ & $13(3.3)$ & $34(8.5)$ & $42(10.5)$ \\
\hline
\end{tabular}

* Not all participants answered any or all of the questions

Table 4. Confidence with research skills

As a result of the workshop, I am able to:

\begin{tabular}{|c|c|c|c|c|}
\hline $\begin{array}{l}\text { Questions } \\
(\mathbf{n}=\mathbf{2 6})^{*}\end{array}$ & $\begin{array}{l}\text { Strongly } \\
\text { Disagree }\end{array}$ & $\begin{array}{l}\text { Generally } \\
\text { Disagree }\end{array}$ & $\begin{array}{l}\text { Generally } \\
\text { Agree }\end{array}$ & $\begin{array}{l}\text { Strongly } \\
\text { Agree }\end{array}$ \\
\hline Use of a computer software & & & 10 & 13 \\
\hline $\begin{array}{l}\text { Do an effective electronic database search of the } \\
\text { literature }\end{array}$ & & 2 & 8 & 13 \\
\hline Critically read a journal research article & & 3 & 8 & 12 \\
\hline Formulate a clear research question & & & 8 & 15 \\
\hline $\begin{array}{l}\text { Choose a research design that will answer my } \\
\text { research question or hypothesis }\end{array}$ & 1 & & 8 & 13 \\
\hline $\begin{array}{l}\text { Identify research variables to collect and where to } \\
\text { collect them from }\end{array}$ & & & 8 & 16 \\
\hline $\begin{array}{l}\text { Design and implement the best strategy for } \\
\text { collecting my samples }\end{array}$ & 1 & 1 & 8 & 11 \\
\hline Analyse the data and tools needed & & 2 & 7 & 14 \\
\hline Who to contact when I need help with my project & & & 5 & 18 \\
\hline How to write the results and findings of my project & & 1 & 10 & 12 \\
\hline Effectively present my study and its implications & 1 & & 7 & 14 \\
\hline TOTAL & $3(\mathbf{0})$ & $9(1)$ & 39 (4) & $151(17)$ \\
\hline
\end{tabular}

* Not all participants answered all the questions 


\subsection{Workshop Evaluation $(n=27)$}

The majority of participants $(24,89 \%)$ agreed that the programme engaged them in active learning and $23(85 \%)$ believed the goals were met. The workshop helped them understand basic concepts and terminology of research design and methods $(25,93 \%)$ and a similar number had developed a research team plan. Feedback

\subsection{Reflection Themes}

The participants' reflective responses were grouped into eight themes and these are listed below with representative statements to illustrate.

\subsubsection{Inspired/Motivated}

The participants felt inspired by their new knowledge and had developed high levels of motivation to do research. "I have always wanted to do research for a long time and have always desired for an opportunity; I have set my goals for an abstract in 4 months and to present a research paper in 2 years time; there have been incidences in the clinical setting that has bothered me that I want to do research on." - nurse

\subsubsection{Research Is Important}

The participants were motivated to do research because they were convinced that research evidence improves the quality of health services. "....made me realise that we must do research and audit to improve our services at all times and also to support other colleagues to participate in research. We could share our data in the region to create multicentre studies in the Pacific." - obstetrician

\subsubsection{Performing Research and Audit Were Possible by Starting with "Small" Research}

Participants learned that it was possible to do research by starting small. Small projects were doable and confidence increases with their completion. "I tend to think that they are very "big things' to do and they may be only what the doctors can do. But now ... "start small", that made me to like doing many audits and research when I go back home." midwife. "I have made a conscious decision to take a common issue per week and write a small commentary and then do an audit - aim to audit at least 2-3 issues per month and perhaps roll on to develop into a multi-country studies" obstetrician

\subsubsection{Perform Research in Parallel with Clinical Work and Use Data Collected at Work}

The participants were now aware that research and clinical audit could be done readily with data collected daily. “...has taught me that we can utilise data available at work to identify problematic areas and find ways to improve and resolve issues." - midwife. "I'm able to think of so many things that we are doing in practice that need to be audited or researched" - midwife.

\subsubsection{Encourage Others to Do Research and Research Is a Team-building Tool}

The participants were convinced that research was so important that everyone in the organisation should be involved. Performing research is team-work and that each member of the team brings a skill and task to the project. "The ways to disseminate and use research/audit results to initiate change was most valuable to me ...Research leadership and team building were also very relevant to my work as the head of the national research department." - doctor (researcher). "It empowered me to do research or an audit so that I can get my staff, medical staff (nurses, doctors, managers, etc.) to realise the facts based on what happened, this will bring us together to work as a team to find solutions." - obstetrician

\subsubsection{Encourage Research Networking in the Region}

There was a strong sense of excitement associated with networking amongst the participants, who felt that collaborative work was possible in the region. "Meeting people from other different Pacific Island countries and establishing the network is the most valuable experience" - obstetrician

\subsubsection{Increased Understanding of a Particular Topic}

The participants had different learning needs and they were keen to point out specific knowledge and skills that were learnt at the workshop. "Understanding ethics and the importance of ethics.....and the need to go through the Ethics Committee and the protection of the participants in a research project." - obstetrician. "I found clinical audit to be more interesting as it is more convenient to my context, and as a novice, doing an audit is like the beginning of my research journey" - midwife.

\subsubsection{Need More Learning of Skills}

There was a distinct feeling amongst the participants that they did not have either individually or collectively as a team, all the skills needed to perform research. "We need help with methods in data application - mean technical aspects e.g. datasets/ Excel spreadsheet so it is easier for stat analysis" - obstetrician. "Better if we had more time to learn skills ...I 
am not very confident yet in performing research." - midwife

\subsection{Identification of Research and Audit Projects}

All the participants agreed to work together as their country's reproductive health clinical research team. They identified research or clinical audit topics, which were then developed further with the assistance of the facilitators. They then outlined their projects to the whole class stating methods, datasets required and potential duration of the projects. Feedback from the class and facilitators were used to refine the projects, which they would need to "sell" to their management on return. Mentors were assigned to assist the participants with their projects.

\section{Discussion}

A good response to an online survey $(63 / 85,74 \%)$ to assess the research needs of Pacific clinicians was important in determining curriculum content of the workshop, which was fully subscribed by selected participants. Most of the 15 Pacific Island countries have limited human capacity to do research (World Health Organization, 2007) and our study is the first to identify, from an online survey, the research needs of clinicians, which revealed essential data that informed curriculum content and suggests that it is possible to conduct well-targeted online surveys in the Pacific (Brown, Gilbert, \& Bruno, 2013). Curriculum content determined by stakeholders and participants is essential in adequately addressing learning needs (Bates et al., 2007) which was, for our workshop, not too dissimilar from the usual set of core topics (Goto et al., 2005) such as epidemiology, statistics, ethics, methods, research principles, process and terminology. The training approaches acknowledged the socio-cultural context of the participants' environment and the datasets and collection methods available in each setting.

There was an overall gain of knowledge amongst the participants from $36 \%$ to $43 \%$ ( $\mathrm{p}<0.008$ ) after the workshop. The obstetricians had a higher baseline knowledge, as would be expected, compared to others and nurses (42\%, 40\%, 30\%), but the absolute gain in research knowledge was significantly higher in the nursing group $(13 \%, 0.04)$ (Table 2$)$. A gain in research knowledge has been shown in three similar workshops held for clinicians in LMIC (Ajuwon \& Kass, 2008; Sunita Dodani \& LaPorte, 2008; Tomatis et al., 2011). What has not been shown in other studies however, is the difference in knowledge gain between nurses and physicians attending the same workshop. There was no knowledge gain amongst the obstetricians whereas there was a significant gain in research knowledge amongst the nurses, which suggests that the workshop was perhaps leaning more to addressing the learning needs of nurses. It is also possible that the doctors had other gains from the workshop, not captured in our questions, as the workshop evaluation (Table 4) did not identify any issues that might have affected the ability of doctors to learn. All the participants agreed that the goals of the workshop were met. Such gains might include satisfaction about advancing projects that were important to them and the prospect of working with mentors. On the other hand, learning outcomes can be affected by a diverse class of learners, from different educational backgrounds, which makes it essential that effective differentiation in instruction applies so that all participants' learning needs are met (Tomlinson, 2014). Whereas separate research workshops for doctors and nurses may better address their individual needs, workshops that includes all cadres of Pacific health workers have been encouraged as the inter-disciplinary discourse and story-telling contributes to better learning and collaborative team-work (World Health Organization, 2010).

Twenty-five $(n=26)$ of the participants had a positive attitude to research and all had an intention to perform research although eight did not have a research project (Table 3), which was one of the inherent benefits of the workshop. Whether motivation and intention translate to action will depend on many factors being fulfilled such as career development, mentoring and existence of a health research system and the reduction of research barriers (Johnston, Crombie, Davies, Alder, \& Millard, 2000; Pager, Holden, \& Golenko, 2012; Willis-Shattuck et al., 2008).

Identified learning themes such as building research teams and starting small with the data one collects every day serve as essential messages for all clinical researchers and managers of health services. The evaluation identified the need to develop research skills and encouraging a research network in the region. Developing research skills and collaborative networks are critical steps in research capacity building programmes (Council on Health Research for Development, 2007) and the research needs analysis identified the skills Pacific clinicians prioritised as important.

It would be a challenge to accommodate all the required knowledge and skills training into a 6-day stand-alone workshop, which would necessitate rethinking the objectives and curriculums of short-term workshops for clinicians who have had not had previous research experience. A series of training workshops and research courses have proven successful in generating publications (Bissell et al., 2014; Goto et al., 2005; Zumla et al., 2010) although others reported non-publication outcomes such as appreciation of the research process (Bates et al., 2007). Increase in research skills, such as conducting a literature search and writing a research proposal will most likely improve confidence to perform research (Unrau \& Beck, 2004). Identified research projects such as determinants of family planning usage and reasons for late booking will, if completed satisfactorily, has the potential to inform health delivery policy. Research mentoring was provided to assist participants to complete their projects. The effectiveness of research workshops for clinicians in 
generating publications has been variable (Ali, 2012; Bates et al., 2007; Buist \& Parry, 2013; Goto et al., 2005; Short, McDonald, Turner, \& Martis, 2010) although a recent research building programme for Pacific Island clinicians, held promise (Bissell et al., 2014) by using a modular series of workshops that resulted in 19 publications from 17 out of 36 (47\%) clinicians. In addition, knowledge or skills gained during workshops need to be repetitively utilised by engaging participants in research work as knowledge gained at workshop was known to deteriorate after a few weeks (Sunita. Dodani, Songer, Ahmed, \& LaPorte, 2012; Yost, Ciliska, \& Dobbins, 2014). Whilst it is acknowledged that it takes many years to train a rounded researcher, satisfactory research output was not always guaranteed (Hyder, Akhter, \& Qayyyum, 2003).

The strength of our study is that it is the only study we are aware of that has determined the knowledge gain at a research workshop aimed at clinicians of a mixed background in LMIC. The workshop evaluation included the 'stages of change' as used elsewhere (Buckley et al., 2003) and identified important research needs and themes order to measure different learning outcomes. A weakness of our study was in the small number of participants, which should caution against generalisations from our methods or outcomes. Small numbers are unavoidable in LMIC. Despite this weakness, this study demonstrates that an effective intervention is possible and identifying significant impact on a small sample is promising. The importance of our paper is adding to the limited international literature on the benefits of research workshops in resource poor settings.

\section{Conclusion}

There is a huge need for clinical research in the Pacific Islands, which is matched by the enthusiasm of the reproductive clinical teams from six Island Countries, in this study, to learn research and audit methods. The importance of stakeholder involvement and a contextualised workshop programme is emphasized. Nurses may have lower research knowledge compared to physicians; however, it has been shown that knowledge acquisition in a multidisciplinary team-learning environment can be empowering for nurses. Future workshops will need adequate and appropriate differentiation of instruction to address the learning needs of all members of a clinical team.

The research team from the Islands identified prioritised research and audit projects that with support of research mentors may result in quality improvement and research publications in the future. Future evaluation will assess the long-term effectiveness of annual research workshops and mentoring support within the BRRACAP project.

\section{Acknowledgements}

Thanks to Dr Christina Tieu and Dr Gokilavani Sekar Chandranfor marking the tests.

\section{References}

Ajuwon, A. J., \& Kass, N. (2008). Outcome of a research ethics training workshop among clinicians and scientists in a Nigerian university. BMC Medical Ethics, 9, 1. http://dx.doi.org/10.1186/1472-6939-9-1

Ali, R. F., Alexander. (2012). Building capacity for clinical research in developing countries: the INDOX cancer research network experience. Global Health Action, 5, 1-6. http://dx.doi.org/10.3402/gha.v5i0.17288

Back, S. E., Book, S. W., Santos, A. B., \& Brady, K. T. (2011). Training physician-scientists: a model for integrating research into psychiatric residency. Academic psychiatry : the journal of the American Association of Directors of Psychiatric Residency Training and the Association for Academic Psychiatry, 35(1), 40-45. http://dx.doi.org/10.1176/appi.ap.35.1.40

Bamako call to action on research for health.). Strengthening research for health, development, and equity. http://www.wpro.who.int/health_research/policy_documents/bamako_global_ministerial_forum.pdf. 2009 Last accessed: 25 March 2014.

Bates, I., Ansong, D., Bedu-Addo, G., Agbenyega, T., Akoto, A. Y., Nsiah-Asare, A., \& Karikari, P. (2007). Evaluation of a learner-designed course for teaching health research skills in Ghana. BMC medical education, 7, 18. http://dx.doi.org/10.1186/1472-6920-7-18

Bissell, K., Viney, K., Brostrom, R., Gounder, S., Khogali, M., Kishore, K., \& Harries, A. D. (2014). Building operational research capacity in the Pacific. Public Health Action, 4(2), S2-S13. http://dx.doi.org/10.5588/pha.13.0091

Brown, A. N., Gilbert, B., \& Bruno, A. F. (2013). Using participatory action research to develop an essential medicine supply competency framework for primary health care personnel in Pacific Island Countries. International Journal of Nursing, 1(2), 13-24.

Buckley, L. L., Goering, P., Parikh, S. V., Butterill, D., \& Foo, E. K. (2003). Applying a 'stages of change' model to enhance a traditional evaluation of a research transfer course. J Eval Clin Pract., 9(4), 385-390. 
http://dx.doi.org/10.1046/j.1365-2753.2003.00407.x

Buist, S., \& Parry, V. (2013). The American Thoracic Society Methods in Epidemiologic, Clinical, and Operations Research Program

A Research Capacity-Building Program in Low- and Middle-Income Countries Ann Am Thorac Soc, 10(4), 281-289. http://dx.doi.org/10.1513/AnnalsATS.201304-081OT

COHRED. (2012). Beyond Aid: Research and innovation as key drivers for health, equity and development. Forum 2012, 24-26 April, Cape Town Africa. ISBN 978-92-9226-054-5.

Cole, D., Kakuma, R., Fonn, S., Izugbara, C., Thorogood, M., \& Bates, I. (2012). Poster - Evaluations of health research capacity strengthening: a review of the evidence.

Council on Health Research for Development. (2007). Are international health research programmes doing enough to develop research systems and skills in low and middle income countries? http://www.cohred.org/downloads/cohred_publications/COHREDStatement2007ResponsibleVerticalProgramming LOWRES.pdf ]. COHRED, Geneva.

Dodani, S., \& LaPorte, R. E. (2008). Ways to strengthen research capacity in developing countries: effectiveness of a research training workshop in Pakistan. Public Health, 122(6), 578-587. http://dx.doi.org/10.1016/j.puhe.2007.09.003

Dodani, S., Songer, T., Ahmed, Z., \& LaPorte, R. E. (2012). Building Research Capacity in Developing Countries: Cost-Effectiveness of an Epidemiology Course Taught by Traditional and Video-Teleconferencing Methods in Pakistan. Telemedicine \& e-Health, 18(8), 621-628. http://dx.doi.org/10.1089/tmj.2011.0262

Ekeroma, A. J., Kenealy, T., Shulruf, B., McCowan, L., \& Hill, A. (2014). Building reproductive health research and audit capacity and activity in the pacific islands (BRRACAP) study: methods, rationale and baseline results. BMC Med Educ, 14(121). http://dx.doi.org/10.1186/1472-6920-14-121

Ekeroma, A. J., Pollock, T., Kenealy, T., Shulruf, B., Sopoaga, F., Montorzi, G., \& Hill, A. (2013). Pacific Island publications in the reproductive health literature 2000-2011: With New Zealand as a reference. ANZJOG. http://dx.doi.org/10.1111/ajo.12039

Goto, A., Nguyen, T. N., Nguyen, T. M., \& Hughes, J. (2005). Building postgraduate capacity in medical and public health research in Vietnam: an in-service training model. Public Health, 119(3), 174-183. http://dx.doi.org/10.1016/j.puhe.2004.05.005

Hyder, A., Akhter, T., \& Qayyyum, K. (2003). Capacity development for health research in Pakistan: the effects of doctoral training. Health Policy and Planning, 18(3), 338-343. http://dx.doi.org/10.1093/heapol/czg040

Johnston, G., Crombie, I., Davies, H., Alder, E., \& Millard, A. (2000). Reviewing audit: barriers and facilitating factors for effective clinical audit. Qual Health Care, 9(1), 23-36. http://dx.doi.org/10.1136/qhc.9.1.23

Kahn, K., Ryan, G., Beckett, M., Taylor, S., Berrebi, C., \& Cho, M. (2011). Bridging the gap between basic science and clinical practice: a role for community clinicians. Implementation Science, 6(34). http://dx.doi.org/10.1186/1748-5908-6-34

Page, J., Heller, R. F., Kinlay, S., Lim, L. L. Y., Qian, W., Suping, Z., Macharia, W. (2003). Attitudes of developing world physicians to where medical research is performed and reported. BMC Public Health, 3, 6. http://dx.doi.org/10.1186/1471-2458-3-6

Pager, S., Holden, L., \& Golenko, X. (2012). Motivators, enablers, and barriers to building allied health research capacity. Journal of Multidisciplinary Healthcare, 5, 53-59. http://dx.doi.org/10.2147/JMDH.S27638

Pang, T., \& Terry, R. F. (2011). WHO/PLoS Collection "No Health Without Research": A Call for Papers. PLoS Med, 8(1). http://dx.doi.org/10.1371/journal.pmed.1001008

Presser, S., Rothgeb, J., \& Couper, M. e. a. (2004). Methods for testing and evaluating survey questions. New Jersey: John Wiley \& Sons,. http://dx.doi.org/10.1002/0471654728

Redman-Maclaren, M. L., Maclaren, D. J., Solomon, J., Muse, A., Asugeni, R., Harrington, H., Clough, A. R. (2010). Research workshop to research work: initial steps in establishing health research systems on Malaita, Solomon Islands. Health Research Policy \& Systems, 8, 33. http://dx.doi.org/10.1186/1478-4505-8-33

Short, J., McDonald, S., Turner, T., \& Martis, R. (2010). Improving capacity for evidence-based practice in South East Asia: evaluating the role of research fellowships in the SEA-ORCHID Project. BMC medical education, 10, 37. http://dx.doi.org/10.1186/1472-6920-10-37 
Smith, S., \& Bingman, B. (2007). Evidence about the Effectiveness of Evidence- based Practice: A Workshop for Training Adult Basic Education, TANF and One-Stop Practitioners and Program Administrators. Cambridge.

Spencer, L., Ritchie, J., \& O'Conner, W. (2003). Qualitative research practices: a guide for social science students and researchers. New York: Sage.

Thomas, D. (2006). A general inductive approach for analysing qualitative evaluation data. American Journal of Evaluation. American Journal of Evaluation, 27(2), 237-246. http://dx.doi.org/10.1177/1098214005283748

Thomas, R., \& Wilson, D. (2010). How to Note: Capacity Building in Research. How to Note. Department for International Development, London.

Tomatis, C., Taramona, C., Rizo-Patron, E., Hernandez, F., Rodriguez, P., Piscoya, A., Estrada, C. A. (2011). Evidence-based medicine training in a resource-poor country, the importance of leveraging personal and institutional relationships. Journal of Evaluation in Clinical Practice, 17(4), 644-650. http://dx.doi.org/10.1111/j.1365-2753.2011.01635.x

Tomlinson, C. A. (2014). Differentiated classroom: Responding to the needs of all learners. Alexandria, VA. USA.: ASCD.

Unrau, Y. A., \& Beck, A. R. (2004). Increasing Research Self-Efficacy Among Students in Professional Academic Programs. Innovative Higher Education, 28(3).

Willis-Shattuck, M., Bidwell, P., Thomas, S., Wyness, L., Blaauw, D., \& Ditlopo, P. (2008). Motivation and retention of health workers in developing countries: a systematic review. BMC Health Services Research, 8, 247. http://dx.doi.org/10.1186/1472-6963-8-247

World Health Organisation Report. (2007). Everybody's Business: Strengthening Health Systems to Improve Health Outcomes: WHO's Framework for Action. Geneva: World Health Organisation.

World Health Organization. (2007). Consultation on Strengthening Health Research Capacity in the Pacific http://www.wpro.who.int/health_research/documents/docs/Meetingreport_Nadi2007.pdf. . Nadi, Fiji.

World Health Organization. (2010). Frameowrk for action on interprofessional education and collaborative practice. http://www.who.int/hrh/nursing_midwifery/en/. Geneva.

Wright, K. B. (2005). Researching Internet-Based Populations: Advantages and Disadvantages of Online Survey Research, Online Questionnaire Authoring Software Packages, and Web Survey Services. Journal of Computer-Mediated Communication, 10(3), 00-00. http://dx.doi.org/10.1111/j.1083-6101.2005.tb00259.x

Yost, J., Ciliska, D., \& Dobbins, M. (2014). Evaluating the impact of an intensive education workshop on evidence-informed decision making knowledge, skills, and behaviours: a mixed methods study. BMC Medical Education, 14(13), http://dx.doi.org/10.1186/1472-6920-14-13

Zumla, A., Huggett, J., Dheda, K., Green, C., Kapata, N., \& Mwaba, P. (2010). Trials and tribulations of an African-led research and capacity development programme: the case for EDCTP investments. Tropical medicine \& international health., 15(4), 489-494. http://dx.doi.org/10.1111/j.1365-3156.2010.02479.x 


\section{Appendix A: Additional questions in the post-workshop questionnaire}

As a result of the workshop, my thoughts about research are... Participants to choose one of four responses

\begin{tabular}{|c|c|c|c|c|}
\hline Questions & $\begin{array}{l}\text { Strongly } \\
\text { disagree }\end{array}$ & $\begin{array}{l}\text { Generally } \\
\text { Disagree }\end{array}$ & $\begin{array}{l}\text { Generally } \\
\text { Agree }\end{array}$ & $\begin{array}{l}\text { Strongly } \\
\text { Agree }\end{array}$ \\
\hline \multicolumn{5}{|l|}{ Learning research skills is important } \\
\hline \multicolumn{5}{|l|}{ Understanding how to do research is important to my work } \\
\hline \multicolumn{5}{|l|}{ I should incorporate research findings into my clinical practice } \\
\hline \multicolumn{5}{|l|}{ I should do more research myself } \\
\hline \multicolumn{5}{|l|}{ Understanding how to do research is relevant to my work } \\
\hline \multicolumn{5}{|l|}{ I plan to learn more about how to do research } \\
\hline \multicolumn{5}{|l|}{$\begin{array}{l}\text { I will bring up the idea of incorporating research into our work } \\
\text { with colleagues }\end{array}$} \\
\hline \multicolumn{5}{|l|}{$\begin{array}{l}\text { I will suggest that we discuss how to improve our use of research } \\
\text { results at our departmental meetings }\end{array}$} \\
\hline \multicolumn{5}{|l|}{ I am currently working on another research project } \\
\hline \multicolumn{5}{|l|}{$\begin{array}{l}\text { I have spoken in a formal meeting (or to my Head of Department) } \\
\text { about increasing the use of research/guidelines in our unit }\end{array}$} \\
\hline \multicolumn{5}{|l|}{$\begin{array}{l}\text { I have suggested casually to some of my colleagues that they } \\
\text { should do research }\end{array}$} \\
\hline \multicolumn{5}{|l|}{ I have changed my clinical practice as a result of doing research } \\
\hline \multicolumn{5}{|l|}{ I plan to include use of research findings in my clinical practice } \\
\hline \multicolumn{5}{|l|}{ As a result of the workshop, I am able to: } \\
\hline \multicolumn{5}{|l|}{ Use a computer and basic software } \\
\hline \multicolumn{5}{|l|}{ Do an effective electronic database search of the literature } \\
\hline \multicolumn{5}{|l|}{ Formulate a clear research question } \\
\hline \multicolumn{5}{|l|}{ Critically read a journal research article } \\
\hline \multicolumn{5}{|l|}{$\begin{array}{l}\text { Choose a research design that will answer my research question or } \\
\text { hypothesis }\end{array}$} \\
\hline \multicolumn{5}{|l|}{$\begin{array}{l}\text { Design and implement the best strategy for collecting my } \\
\text { samples }\end{array}$} \\
\hline \multicolumn{5}{|l|}{ Analyse the data and tools needed } \\
\hline \multicolumn{5}{|l|}{ Who to contact when I need help with my project } \\
\hline \multicolumn{5}{|l|}{ How to write the results and findings of my project } \\
\hline \multicolumn{5}{|l|}{ Effectively present my study and its implications } \\
\hline What experiences have you had to explain your level of research co & ence? & & & \\
\hline
\end{tabular}




\section{Appendix B: Workshop Evaluation Questionnaire - process and delivery of goals}

Part A: The following questions had a scale of four from Disagree to Agree and a No Reply column. The pre-workshop communications gave me the information I needed to learn about and prepare for the workshop.

Materials on the website were useful in preparing for the workshop.

The design of the workshop facilitated exchange of expertise among participants.

The workshop program engaged me in active learning related to its goals.

The workshop sessions were well facilitated.

The logistics for the workshop were well executed.

I believe the goals of the workshop as stated were met:

- Understand approaches to research and audit and their connection to practice and policy

- Understand basic concepts and terminology of research design and methodology.

- Learn skills in literature search, data collection, analysis, report writing, publication and presentation

- Identify drivers and enablers of research/audit practice and how they can be used to generate research action and activity in the workplace

- $\quad$ Develop a personal and team research plan that aligns with research priorities in the participants service/department/ministry of health.

- Understand how to continually learn and perform clinical research and audit, access and promote relevant research evidence in the workplace, and advocate for evidence in policy and clinical practice.

Part B: Open-ended responses

- What aspects of the workshop were the most valuable for you? And why?

- Least valuable and why?

- How has this research workshop changed your thinking about your clinical/management practice/work?

- Reflecting on your interactions at this workshop, are there people with whom you plan to do research with? Be in contact with? If so, list up to five. Please indicate any new contacts with an asterisk (*) following their name.

- Have you identified a personal or team clinical research or audit project during the workshop? If you have, what are your plans in moving the project forward when you return home? This information will be shared with your mentor.

- If your research mentor were to follow up with you as to how you used or applied what you learned, what timeframe would make the most sense for your plans?

- Comment on length and contents of the topics/sessions and language spoken during the workshop.

- Relevancy of topics to what you plan for your research/audit work:

- Which topics/ sessions did you find most and least interesting? Please list.

- Are there topics that should be included?

- Do you have any suggestions for improving future research workshops?

This work is licensed under a Creative Commons Attribution 3.0 License. 